International Journal of Dentistry and Oral Science (JJDOS)

ISSN: 2377-8075

\title{
Healing of an Advanced Endo-Perio Lesion after Sole Endodontic Therapy
}

Alzahrani $\mathrm{A}^{1}$, Taher Al Omari ${ }^{2 *}$

${ }^{1}$ Saudi Endodontic Board Resident, AL Hada Military Hospital, Alhada, Saudi Arabia.

${ }^{2}$ Consultant Endodontist, AL Hada Military Hospital, Alhada, Saudi Arabia.

\begin{abstract}
The Management of combined endodontic-periodontal lesions is complicated, it requires both endodontic therapy and periodontal regenerative surgery procedure in most of the time.

The accurate diagnosis, proper case selection, and the use of modern techniques are factors that will promote healing following endodontic therapy and that was implied here.

This clinical case report presents successful management of a combined endodontic-periodontic lesion affecting the left mandibular first molar which was treated with single-visit root canal treatment that completely healed within one year without any periodontal therapy.
\end{abstract}

\section{*Corresponding Author:}

Dr. Taher Al Omari,

Consultant Endodontist, AL Hada Military Hospital, Alhada,

Saudi Arabia.

Tel: 00966569780866

E-mail: t_omari@yahoo.com

Received: October 11, 2015

Accepted: October 30, 2015

Published: November 03, 2015

Citation: Alzahrani A, Taher Al Omari (2015) Healing of an Advanced Endo-Perio Lesion after Sole Endodontic Therapy. Int J Dentistry Oral Sci. 2(11), 163-167. doi: http://dx.doi.org/10.19070/2377-8075-1500034

Copyright: Taher $\mathbf{A l} \mathbf{O m a r i}^{\circ}$ 2015. This is an open-access article distributed under the terms of the Creative Commons Attribution License, which permits unrestricted use, distribution and reproduction in any medium, provided the original author and source are credited.

\section{Introduction}

A cause-effect relationship between the microbial infection of the root canal system and the development of apical periodontitis has been well-established [1]. Preoperative periapical tissue status is the ultimate prognostic factor influencing the outcome of primary root canal treatment $[2,3]$. The treatment aim of apical periodontitis should be the removal of the cause, i.e. bacterial eradication. Mechanical debridement combined with antibacterial irrigant can render $40-60 \%$ of the treated teeth bacteria-negative based on cultural investigation techniques $[4,5]$. Several studies have elucidated beneficial further reduction in bacterial load subsequent to utilizing calcium hydroxide as an intra-canal medicament for at least one week [6-8]. Despite that, numerous studies and systematic reviews evaluating the effectiveness (healing rates) and post treatment pain of single-versus multiple-appointment root canal treatment for necrotic pulp with apical periodontitis have reported no significant differences between these two treat- ment regimens [9-12].

Historically the effect of periodontal disease on the dental pulp has been a source of discussion of the past century. Only in recent years the reverse has been discussed, the potential effect that a tooth with a necrotic pulp may pose as a risk factor in the initiation and progression of periodontal disease [13]. When the pulp becomes necrotic, there is a direct inflammatory response by the periodontal ligament at the apical foramen and/or opening of accessory canals [14]. Simon et al [15] classified endodonticperiodontal lesions (Endo-Perio lesion) into five different categories. Formulating a differential diagnosis among combined lesions has been challenging because most often clinicians do not have a complete history of the course of disease progression. However, in combined cases particularly, Primary endodontic disease with secondary periodontal involvement, untreated infected canal have already caused periodontal breakdown. In such cases, when endodontic treatment is preformed alone, only part of the lesion will heal to the level of the secondary periodontal lesion. Therefore, the treatment of endodontic-periodontal combined lesions requires both endodontic therapy and periodontal regenerative surgery procedure [16].

This clinical report presents successful management of a combined endodontic-periodontic lesion affecting the left mandibular first molar which was treated with Single-visit root canal treatment that completely healed within one year without any periodontal therapy.

\section{Case Report}

A 31-year-old Saudi female patient, referred from a general dentist for endodontic assessment of tooth \#36 in Jan./2012. On clinical examination, the patient was asymptomatic, a sinus tract was found apically on the mesiobuccal aspect related to left mandibular first molar \#36, and the tooth had class II amalgam filling 
(OD). The radiographic finding revealed a closed apex associated with very large periradicular radiolucency extended laterally and coronally to the alveolar bone localized to the offending tooth (Figure 1). Periodontal probing were within normal limits for all control teeth (\#46, \#16, \#34, and \#35). Whereas there was an extensive buccal bone loss with a pocket had a broad coronal opening, probing depth range between $8-10 \mathrm{~mm}$ for the offending tooth \#36, there was a grade II furcation involvement (Table 1). Diagnostic tests were shown in (Table 2), sensibility tests show no pulp response upon cold (Endo Ice; Hygenic Corp, Akron OH ) and electric pulp tester (EPT) tests in contrast with the finding of control teeth, no tenderness on Percussion and palpation was noted, the mobility of this tooth was grade II. The clinical diagnosis was pulp necrosis with chronic apical abscess. The presence of deep probing depth of all the buccal sites in conjunction with a grade II furcation involvement and mobility grade II indicate the lesion was extended to the periodontal attachments. However, the localized marginal bone loss and absence of calculus classified this lesion as Primary endo/secondary perio lesion [15]. The patient was informed that both endodontic and periodontic interventions would be needed with at least three-months delay between both in order to evaluate body response for the endodontic intervention first. She was also informed that the expected prognosis was questionable due to the advanced periodontal tissue lost.

After local anesthesia (Lidocaine 1:200.000 epinephrine), rubber dam was placed. Access cavity were done by diamond Endo Access bur \#1, and Endo Z bur (Dentsply Maillefer, Switzerland). Under Dental Operating microscope DOM (Zeiss, Oberkochen, Germany) there were evident only of four canals, mesiobuccal ( $\mathrm{MB})$, mesiolingual (ML), distobuccal (DB) and distolingual (DL). Instrumentation of the canals was completed using the Revo-S system (Micro-Mega, Besancon, France) combined with 5.25\% sodium hypochlorite $(\mathrm{NaOCl})$ irrigation delivered with double side-vented (Endo-Irrigation Needle; Transcodent, Germany). The root canal was shaped and cleaned to the apical terminus of pulp that confirmed with Root ZX apex locator (J. Morita Co., Kyoto, Japan). Before obturation, Endo Activator irrigation system (Dentsply, York, USA) was used to agitate EDTA for 1 minute then the final flush of $5.25 \% \mathrm{NaOCl}$. The offending tooth was obturated with continuous wave compaction thermal technique (CWCT) of gutta-percha and pulp canal sealer EWT (SybronEndo, Orange, CA, USA) the immediate coronal sealing was double sealed with; cavit (3M ESPE AG, Seefeld, Germany) + GIC (Fuji II; G.C. International, Scottsdale, AZ), (Figure 2 and Figure 3). Patient was referred back to GDP for amalgam restoration that was placed after two weeks (Figure 4). After 10 months crown was fabricated as final coronal seal.

Patient was recalled for follow up every 3 months up to one year, then yearly for 3 years (Figure 5). In each recall clinical and radiographic assessments (digital radiograph, Kodak RVG 5100, Rochester, USA) were performed. Cone beam computerized tomography (CBCT, carestream CS-9300, Kodak, Rochester, USA) was taken after three years to evaluate the healing. Tooth continued to be asymptomatic, sinus tract was resolved and mobility and probing were restored to normal. Furthermore, CBCT images showed regeneration of buccal bone plate with no signs of disease (Figure 6).

\section{Discussion}

Accurate diagnosis, proper case selection, and the use of modern techniques are factors that will promote healing following endodontic therapy. These procedures are based upon known biological principles incorporated into the technique triad, specifically: biomechanical preparation of the canal system, debridement and disinfection, and three-dimensional obturation of the prepared canals. Each of these objectives must be achieved in order to ensure a successful result. However, Endo-Perio lesion is a true challenge. The radiographic appearance of such lesion may be similar to that of a vertically fractured tooth, hence management requires thorough understanding of wound healing process involving both endodontic and periodontal complex [15].

There is a lack of studies assessing the non-surgical root canal treatment outcome of combined endo-perio lesion. However, few studies assess the outcome of preapical surgery for such combined lesions. Kim \& Kratchman [17] classified periradicular lesions into categories A-F. Lesion types A, B, and C represent lesions of endodontic origin and are ranked according to increasing

Figure 1. preoperative radiograph, showing the large lesion that related to tooth \#36.

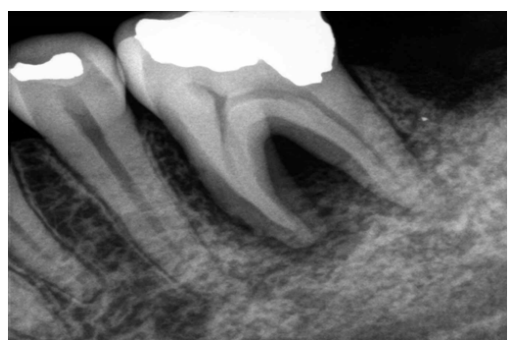

Table 1. Periodontal probing depth in $\mathrm{mm}$, teeth \#34, 35, 26 and 46 were selected as controlled teeth and the offending tooth is \#36.

\begin{tabular}{|c|c|c|c|c|c|c|c|}
\hline Tooth \# & $\mathrm{MB}(\mathrm{mm})$ & B $(\mathrm{mm})$ & $\mathrm{DB}(\mathrm{mm})$ & $\mathrm{DL}(\mathrm{mm})$ & $\mathrm{L}(\mathrm{mm})$ & $\mathrm{ML}(\mathrm{mm})$ & Furcation \\
\hline 34 & 3 & 3 & 3 & 3 & 4 & 4 & \\
\hline 35 & 3 & 4 & 4 & 3 & 4 & 3 & \\
\hline 36 & 8 & 10 & 9 & 4 & 5 & 4 & II \\
\hline 26 & 2 & 3 & 3 & 3 & 2 & 2 & \\
\hline 46 & 2 & 3 & 3 & 3 & 3 & 2 & \\
\hline
\end{tabular}


Table 2. Diagnostic clinical tests.

\begin{tabular}{|c|c|c|c|c|c|c|c|}
\hline Tooth & Cold & EPT & Percussion & Palpation & Mobility & Discolor & Bite Stick \\
\hline 34 & + & + & Non Tender & Non Tender & WNL & No & WNL \\
\hline 35 & + & + & Non Tender & Non Tender & WNL & No & WNL \\
\hline 36 & - & - & Non Tender & Non Tender & II & No & WNL \\
\hline 26 & + & + & Non Tender & Non Tender & WNL & No & WNL \\
\hline 46 & + & + & Non Tender & Non Tender & WNL & No & WNL \\
\hline
\end{tabular}

$(+)$ pulp response; (-) No pulp response, (WNL) within normal limit.

Figure 2. Intermediate Obturation radiograph before coronal seal.

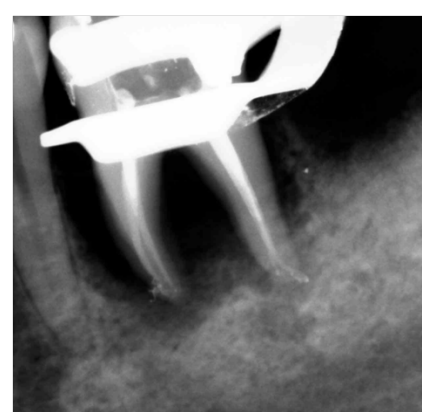

Figure 3. Immediate postoperative radiograph, A. straight angulation, B. Mesial angulation, Note the radiograph projection between MB canal and ML canals that resemble middle canal.
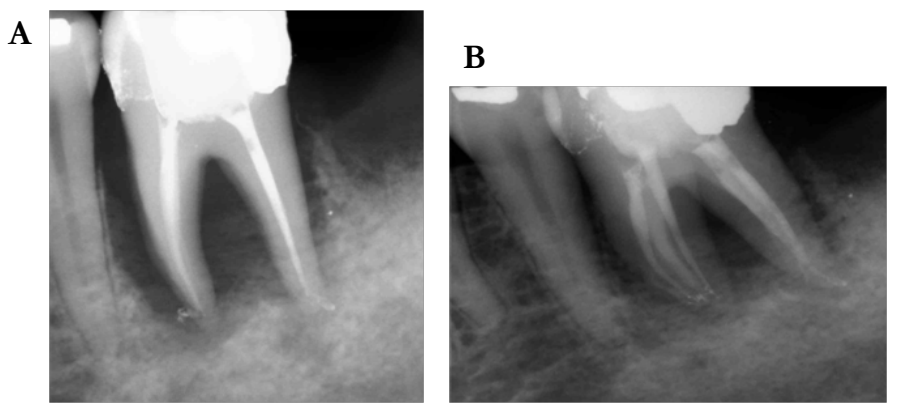

Figure 4. Two weeks later, after coronal seal with amalgam restoration.

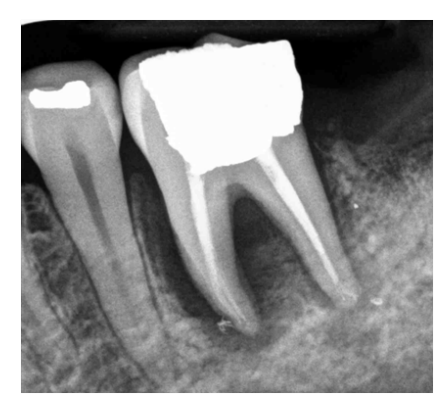

size of periradicular radiolucency. Lesion types D, E, and F represent lesions of combined endodontic-periodontal origin and are ranked according to the magnitude of periradicular breakdown [18]. Many studies have been conducted in an attempt to examine the success of microsurgical methods which include only isolated endodontic lesions. In contrast, relatively fewer studies have applied modern periradicular microsurgical techniques evaluating outcomes of cases involving the combined endodontic-periodontal lesions. However, when buccal or lingual bone lost a successful outcome is reduces dramatically which ranged from 32\% (traditional surgery) to $70 \%$ (microsurgery) [17-20].

The most common clinical/radiographic features of the endodontic-periodontal lesions reported were the periapical radiolucency and deep pocket with a nonvital pulp status. Guided tissue regeneration (GTR) is strongly indicated in cases with a communication of periodontal pocket with periapical lesions, compromised bifurcation or trifurcation crests, and dehiscence with buccal or lingual bone loss $[21,22]$. However, healing in the present case took place without any periodontal intervention. Despite the presence of the extensive periodontal attachment loss (Large radiolucent, extensive buccal bone loss with a wide pocket, probing depth $\geq 8 \mathrm{~mm}$, mobility grade II, furcation involvement grade II and presence of sinus tract in the buccal vestibule).

$\mathrm{Ng}$ et al [23] demonstrated eleven [11] prognostic factors improve periapical healing significantly, achievement of patency at the canal terminus, extension of canal cleaning as close as possible to its apical terminus, the use of (EDTA) solution as a penultimate wash followed by final rinse with $\mathrm{NaOCl}$ solution, and presence 
Figure 5. Follow up recall radiograph. A. and B. Three months recall.; C. and D. Six months recall ; E. and F. Nine months recall; G. and $\mathrm{H}$. One year recall.

A

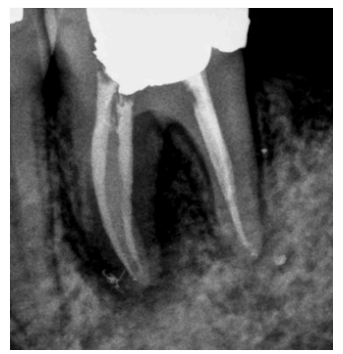

B

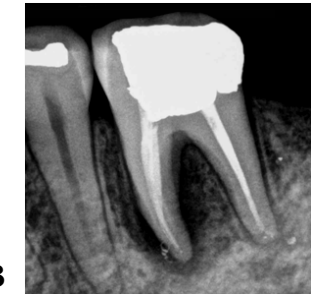

C

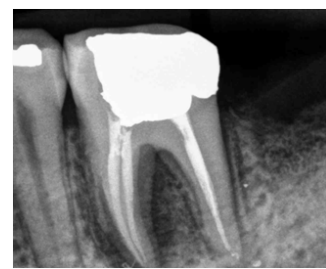

D

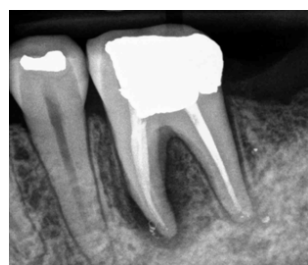

$\mathbf{E}$

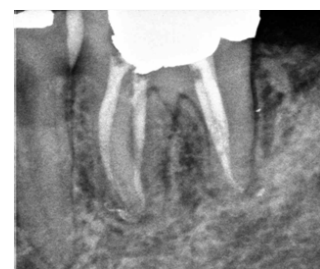

$\mathbf{F}$

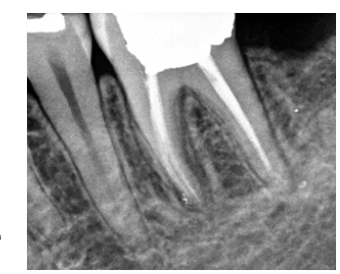

G

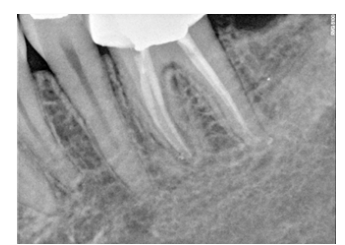

$\mathbf{H}$

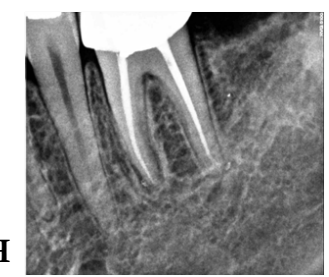

Figure 6. CBCT recall after 3 years. A, axial view of apical third. B, axial view of middle third. C, coronal view, to evaluate the intraradicular bone healing. D, sagital view for Distal root. E. sagital view for Mesial root.
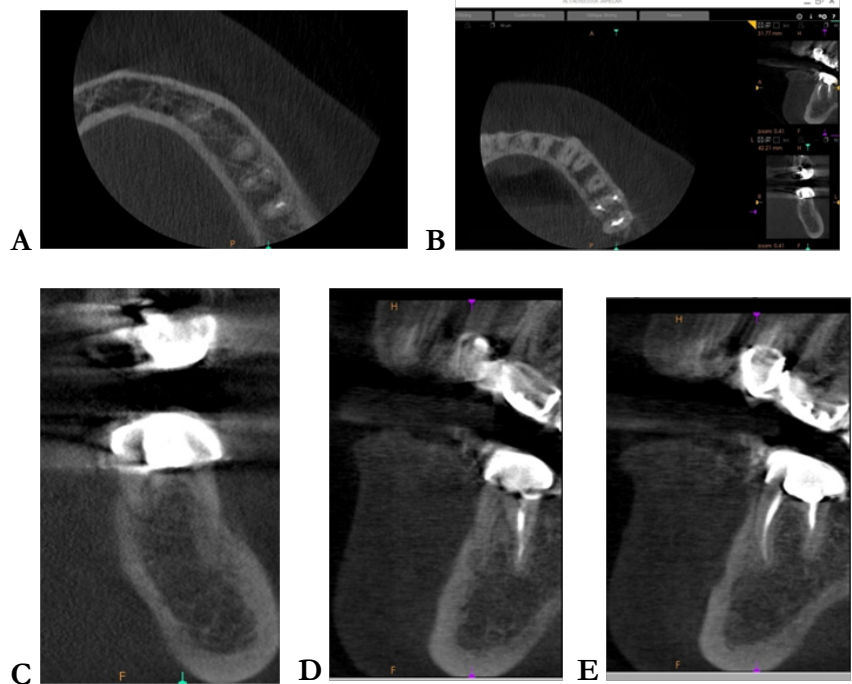

of a satisfactory coronal restoration were implemented in this case. Moreover, the successful outcome seen in the current case report is in line with previous studies indicating high success rates of single visit treatment [9-12].

The prompt healing of this case confirmed the lesion is primary Endo and secondary Perio. There might be two explanations for such healing. The first explanation is related to the age of patient
(31 years), it is well known that the rate of bone remodeling is higher in young patient than older groups. Aging of bone results in greater porosity and decreased of mineralization, with aging, arteriosclerotic changes of blood vessels increases and the viscosity of connective tissue is altered, making repair more difficult, although, in many studies age has not been significantly associated with the outcome $[2,3,24]$. 
A second possible explanation is that the effective treatment protocol of cleaning and shaping of the root canal system leads to a great reduction of the biofilm colonies existing in the inaccessible root canal area. Irrigation with $\geq 0.5 \%$ sodium hypochlorite considerably improves bacterial elimination, resulting in 50 to $80 \%$ negative cultures, and over $99 \%$ reduction in bacterial counts, from an order of $10^{5}$ to $10^{2},[4-6,25,26]$. Activation of irrigation was done by EndoActivator, which is sonic irrigation and is different from ultrasonic irrigation because it operates at a lower frequency. It was reported to be able to effectively clean debris from lateral canals, remove the smear layer, and dislodge clumps of simulated biofilm within the curved canals of molar teeth $[27,28]$.

Assessment of healing was done by periapical radiograph every 3 months combined with clinical examination, and yearly after the first year. Crown placement was planed in a year following the treatment were as coronal seal was established earlier by permanent restoration. CBCT was taken after 3 years for implant placement purposes in the area of tooth \#37, and it was confirmed the previous periapical radiograph findings as shown in (Figure 6). Moreover, CBCT view confirmed that there was no middle mesial canal in conjunction with DOM finding. However, there was a remarkable radiopacity that was coincident with the clinical findings at the time of treatment (Figure 3). It was suspected to be a result of the $\mathrm{X}$-ray projection due to kidney shape mesial root configuration.

Although, it cannot be exclude the possibility of the presence of a wide and deep isthmus in which the lower voxel size $(0.09 \mathrm{~mm})$ of the CBCT could not detect it and that the canal was filled with sealer initially that resorbed during the healing period. The authors are in favor of the first explanation.

\section{Conclusion}

The management of this tooth opened the horizon of the clinician to the outmost power of mechanical debridement combined with antibacterial irrigation. Periodontal therapy should be delayed if there is a considerable sign of healing after 3 months recall, especially in case of primary endodontic and secondary periodontic lesion. However, a randomized clinical trials or prospective studies should be carried out to investigate this assumption.

\section{Acknowledgement}

The authors deny any conflicts of interest with subjects or materials discussed in this manuscript.

I affirm that I/We have no financial affiliation (e.g., employment, direct payment, stock holdings, retainers, consultantships, patent licensing arrangements or honoraria), or involvement with any commercial organization with direct financial interest in the subject or materials discussed in this manuscript, nor have any such arrangements existed in the past three years. Any other potential conflict of interest is disclosed.

\section{References}

[1]. Kakehashi S, Stanley HR, Fitzgerald RJ (1965) The effects of surgical exposures of dental pulps in germ-free and conventional laboratory rats. Oral Surg Oral Med Oral Pathol 20: 340-349.

[2]. Sjögren U, Huggland B, Sundqvist G, Wing K (1990) Factors affecting the long-term results of endodontic treatment. J Endod 16(10): 498-504.

[3]. Friedman S, Abitbol S, Herenia PL (2003) Treatment outcome in endodontics: the Toronto Study. Phase I: Initial treatment. J Endod 29(12): 787-793.

[4]. Byström A, Sundqvist G (1983) Bacteriologic evaluation of the effect of 0.5 percent sodium hypochlorite in endodontic therapy. Oral Surg Oral Med Oral Pathol 55(3): 307-312.

[5]. Sjögren U, Figdor D, Persson S, Sundqvist G (1997) Influence of infection at the time of root filling on the outcome of endodontic treatment of teeth with apical periodontitis. Int Endod J 30(5): 297-306.

[6]. Trope M, Delano EO, Ørstavik D (1999) Endodontic treatment of teeth with apical periodontitis: single vs multivisit treatment. J Endod 25(5): 345350.

[7]. Sjögren U, Figdor D, Spangberg L, Sundqvist G (1991) The antimicrobial effect of calcium hydroxide as a short-term intracanal dressing. Int Endod J 24(3): 119-125.

[8]. Ørstoavik D, Kerekes K, Molven O (1991) Effects of extensive apical reaming and calcium hydroxide dressing on bacterial infection during treatment of apical periodontitis: a pilot study. Int Endod J 24(1): 1-7.

[9]. Figini L, Lodi G, Gorni F, Gagliani M (2008) Single versus multiple visits for endodontic treatment of permanent teeth: a Cochrane systematic review. J Endod 34(9): 1041-1047.

[10]. Sathorn C, Parashos P, Messer HH (2005) Effectiveness of single- versus multiple-visit endodontic treatment of teeth with apical periodontitis: a systematic review and meta-analysis. Int Endod J 38(6): 347-355.

[11]. Sathorn C, Parashos P, Messer H (2008) The prevalence of postoperative pain and flare-up in single- and multiple-visit endodontic treatment: a systematic review. Int Endod J 41(2): 91-99.

[12]. Su Y, Wang C, Ye L (2011) Healing Rate and Post-obturation Pain of Single- versus Multiple-visit Endodontic Treatment for Infected Root Canals: A Systematic Review. J Endod 37(2): 125-132.

[13]. Harrington GW, Steiner DR, Ammonas WF (2002) The periodontal-endodontic controversy. Periodontol 2000 30: 123-130.

[14]. Seltzer S, Bender IB, Nazimov H, Sinai I (1967) Pulpitis-induced interradicular periodontal changes in experimental animals. J Periodontol 38(2): 124-129.

[15]. Simon JH, Glick DH, Frank AL (1972) The relationship of endodonticperiodontic lesions. J Periodontol 43(4): 202-208.

[16]. Oh SL, Fouad AF, Park SH (2009) Treatment strategy for guided tissue regeneration in combined endodontic-periodontal lesions: Case report and review. J Endod 35(10): 1331-1336.

[17]. Kim S, Kratchman S (2006) Modern endodontic surgery concepts and practice: a review. J Endod 32(7): 601-623.

[18]. Kim E, Song JS, Jung IY, Lee SJ, Kim S (2008) Prospective clinical study evaluating endodontic microsurgery outcomes for cases with lesions of endodontic origin compared with cases with lesions of combined periodontalendodontic origin. J Endod 34(5): 546-551.

[19]. Hirsch JM, Ahlstrom U, Henrikson PA, Heyden G, Peterson LE (1979) Periapical surgery. Int J Oral Surg 8(3): 173-185.

[20]. Skoglund A, Persson G (1985) A follow-up study of apicoectomized teeth with total loss of the buccal bone plate. Oral Surg Oral Med Oral Pathol 59(1): 78-81.

[21]. Pecora G, Kim S, Celletti R, Davarpanah M (1995) The guided tissue regeneration principle in endodontic surgery: One-year postoperative results of large periapical lesions. Int Endod J 28(1): 41-46.

[22]. Sharma R, Hegde V, Siddharth M, Hegde R, Manchanda G, et al. (2014) Endodontic-periodontal microsurgery for combined endodontic-periodontal lesions: An overview. J Conserv Dent 17(6): 510-516.

[23]. Ng YL, Mann V, Gulabivala K (2011) A prospective study of the factors affecting outcomes of nonsurgical root canal treatment: Part 1: periapical health. Int Endod J 44(7): 583-609.

[24]. Ng YL, Mann V, Rahbaran S, Lewsey J, Gulabivala K (2008) Outcome of primary root canal treatment: Systematic review of the literature - Part 2. Influence of clinical factors. Int Endod J 41(1): 6-31.

[25]. Bystrom A, Sundqvist G (1985) The antibacterial action of sodium hypochlorite and EDTA in 60 cases of endodontic therapy. Int Endod J 18(1): 35-40.

[26]. Dalton BC, Orstavik D, Phillips C, Pettiette M, Trope M (1998) Bacterial reduction with nickel-titanium rotary instrumentation. J Endod 24(11): 763-767.

[27]. de Gregorio C, Estevez R, Cisneros R, Heilborn C, Cohenca N (2009) Effect of EDTA, sonic, and ultrasonic activation on the penetration of sodium hypochlorite into simulated lateral canals: an in vitro study. J Endod 35(6): 891-895.

[28]. Klyn SL, Kirkpatrick TC, Rutledge RE (2010) In vitro comparisons of debris removal of the EndoActivator system, the F file, ultrasonic irrigation, and $\mathrm{NaOCl}$ irrigation alone after hand-rotary instrumentation in human mandibular molars. J Endod 36(8): 1367-1371. 